\title{
Interaction of Pavement and Soil When Pillar Abutment was Excavated
}

\section{Zheng Guodong ${ }^{1, a}$, Hou Enpin ${ }^{2,}$, Zhu Dengyuan $^{3, \text { a }}$}

${ }^{1}$ School of civil engineering \& architecture, Linyi University, Linyi, Shandong, 276005, China

\author{
azhengguodong@lyu.edu.cn, houenpin@qq.com, ${ }^{\mathrm{c}}$ zhudengyuan@lyu.edu.cn
}

Keywords: Stability; sleeve-valve-pipe grouting; bolt support; excavation sequence

\begin{abstract}
The proper excavation sequence of comprehensive strengthening remolded soil method of combining sleeve-valve-pipe grouting and bolt support was studied for the abutment backfill stability problems when the retaining wall in front of pillar abutment was excavated which was often encountered in the construction process of highway reconstruction and extension. With ANSYS software, the strength reduction method was used to analyze the safety factor of slope excavation of different excavation programs to determine the most rational excavation program.
\end{abstract}

\section{Preface}

The construction sequence of slope excavation has a greater impact on slope stability [1-2], even though the slope design is in line with requirements for the safety factor. But if the methods of construction are improper it will still cause slope instability [3-4]. For the object of slope engineering is a complex geological body, to make an objective assessment of the stability, we must not only study the geological conditions of slope engineering, geotechnical physical characteristics, slope body deformation and failure mechanism and stability, but also study the influence of slope excavation style and support measures on slope stability [5-6]. Computer numerical simulation theory and methods were developed. These theories and methods provide new methods and tools for landslide, slope engineering evaluation and failure mechanisms and the stability of the deformation [7-8].

\section{Introduction of the project}

Table 1 Abutment backfill and foundation soil engineering properties

\begin{tabular}{|c|c|c|c|c|c|c|c|c|c|c|c|}
\hline soil & $\begin{array}{c}\text { dry } \\
\text { densit } \\
y\end{array}$ & $\begin{array}{c}\text { wet } \\
\text { density }\end{array}$ & $\begin{array}{c}\text { water } \\
\text { content }\end{array}$ & $\begin{array}{c}\text { liquid } \\
\text { limit }\end{array}$ & $\begin{array}{l}\text { plastic } \\
\text { limit }\end{array}$ & $\begin{array}{l}\text { plasticity } \\
\text { index }\end{array}$ & $\begin{array}{c}\text { nonuniform } \\
\text { coefficient }\end{array}$ & $\begin{array}{c}\text { curvature } \\
\text { coefficient }\end{array}$ & $\begin{array}{l}\text { modulus } \\
\text { of } \\
\text { resilience }\end{array}$ & $\begin{array}{c}\text { internal } \\
\text { friction } \\
\text { angle }\end{array}$ & adhesion \\
\hline & $/ \mathrm{kg} \cdot \mathrm{m}$ & $/ \mathrm{kg} \cdot \mathrm{m}^{-}$ & $1 \%$ & $1 \%$ & $/ \%$ & IP & $\mathrm{C}_{\mathrm{u}}$ & $\mathrm{C}_{\mathrm{c}}$ & /MPa & 10 & $/ \mathrm{kPa}$ \\
\hline $\begin{array}{c}\text { coarse } \\
\text { grained } \\
\text { soil }\end{array}$ & 2140 & 2310 & 8.20 & 29.0 & 23.2 & 5.8 & 23.7 & 0.55 & 65 & 30 & 45 \\
\hline $\begin{array}{l}\text { fine } \\
\text { grained } \\
\text { soil }\end{array}$ & 1670 & 1970 & 17.47 & 29.2 & 22.7 & 6.5 & 12.4 & 0.52 & 50 & 28 & 20 \\
\hline
\end{tabular}

The project is located in Linyi segment of Rilan highway. The \# 3 abutment at K100+462 of the separate overpass is intersected with the widening Zhang-Nan Road. The settlement difference between the abutment and embankment fill is about $80 \mathrm{~mm}$. The soil is engineering classified as coarse grained soil with a filling height of $8 \mathrm{~m}$. The depth of foundation soil is $15 \mathrm{~m}$, and the bedrock is under the soil. The abutment backfill and foundation soil engineering properties which were got after a review of the geological exploration data, field sampling and laboratory experiments are shown in Table 1. 


\section{Numerical simulation and main conclusions}

ANSYS8.0 software was used to build a three-dimensional elastic-plastic numerical model of the front slope of pillar abutment. The bridge with the slope of soil excavation was simulated. In particular, in the most disadvantaged sectors of construction the impact of jumping dynamic loading on pile cap displacement was simulated and analyzed.

The pile distribution of the horizontal displacement along the bridge in an excavation process is shown in Fig.1. With the progress of the vertical excavation, the horizontal displacement of the pile is increasing. When three stage excavation of the lane is completed, the largest horizontal displacement of the pile top was up to $0.7 \mathrm{~mm}$. When staging and grading excavation is completed, the horizontal displacement of the pile top is near $2 \mathrm{~mm}$. The displacement changes of pile top react construction displacement of the bridge abutment cap. Retaining wall transformation construction of slope makes the abutment cap of bridge compresses the bridge length. The displacement change of $2 \mathrm{~mm}$ is in the acceptable range. Because of embedded rock constraints at the bottom of the pile and the support of soil in front of the wall, the horizontal displacement of pile was distributed in "S" shape. The convex shape of the pile below the original ground demonstrated that the soil had a deformation tendency of slip movement and the pile above the original ground formed a cantilever pile.

The impact dynamic time-history of horizontal displacement at the top of the pile. The impact dynamic time-history curve of horizontal displacement along the bridge at the top of the pile was given in Fig.2. R, L, C respectively was the transverse pile code below the cap, where $\mathrm{R}$ is the inside pile, $\mathrm{L}$ is the outside pile and $\mathrm{C}$ is the center pile.

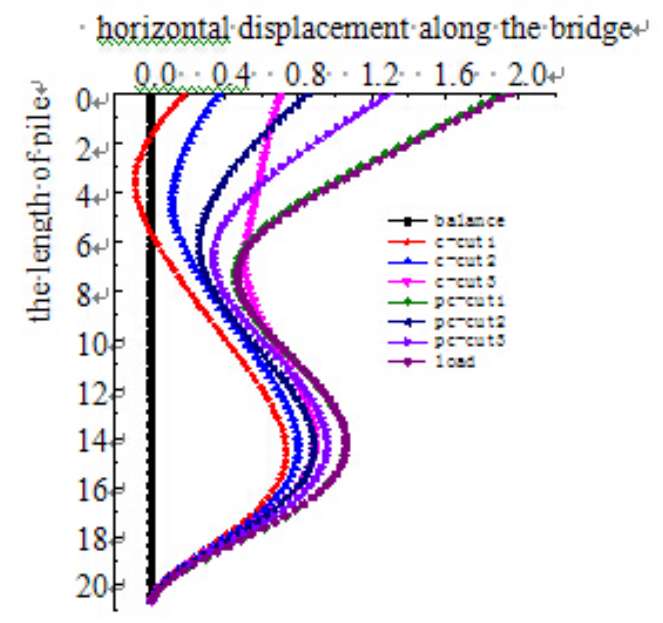

Fig.1 Distribution of horizontal displacement of the pile body along during the excavation

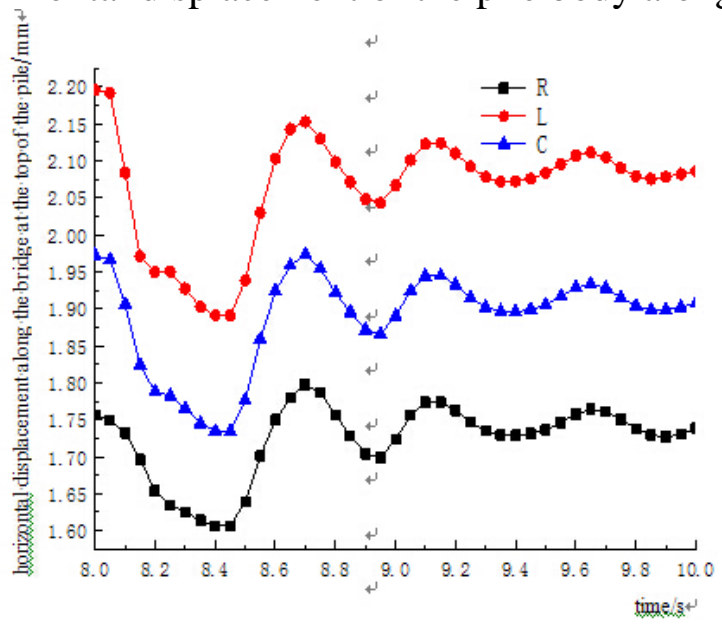


Fig.2 dynamic time-history curve the bridge of horizontal displacement along the bridge at the top of the pile

From Fig.2, during the construction process of retaining wall of the slope, horizontal displacement of the outside pile was more influenced by the slope excavation than the inside one; when the pile was effected by the jumping impact force at the end of bridge, the horizontal displacement fluctuations in each pile was basically consistent, but the fluctuation amplitude of the outside pile was larger than the inside one; the horizontal displacement at the top of pile under load decreased firstly and then increased, showing a wavy attenuation. It reached a trough at the $0.45 \mathrm{~s}$ and a peak at the time of $0.67 \mathrm{~s}$. The reasons of this phenomenon were the spread of volatility and the lag of dynamic response of the earth.

Numerical simulation of spatial effects and the stability of slope excavation. Currently, in pit design, Rankine or Coulomb theory are used in active and passive earth pressure calculation. In essence, these theories only apply to plane problems. For the pit, the broken shape of soil of the inner wall clearly shows a three-dimensional space situation. There has a significant correlation between the soil pressure and ratio of width to height. Earth pressure measured results show that when ratio of width to height of the pit $\mathrm{W} / \mathrm{H}<5$, there is an obvious arching effect in the rupture body behind the pit. Such usage of arching spatial effect is beneficial to controlling soil excavation stability of the pit, but the ratio of width to height of the pit excavation is related to the size of the arch and has no response to the stability of the soil within the arch. The collapse and fall of soil within the arch also cause damage to the project, and is also unacceptable.

The impact of the excavation segment width on the stability in retaining wall construction of the slope was relatively large. The interval excavation by troughs construction method was using the support and restraints of the soil section which was not excavated on the soil section which had been excavated to increase the security and stability of retaining wall construction of the slope. But with the increase in the width of the excavation section, the role of support and restraint reduced. In order to determine a reasonable excavation segment width of the slope soil and ensure the security and stability of slope excavation. Numerical simulations were carried out in different construction excavation height and excavation width cases to calculate the security and stability factor with the strength reduction method. The segment excavation width was determined according to the changes of the safety factor.

A three-dimensional elastic-plastic analysis model is built with ANSYS finite element analysis software. Considering the symmetry of the problem, we take the $1 / 2$ model. The model width is $60 \mathrm{~m}$ and the height of the foundation is $15 \mathrm{~m}$. The roadbed height varies with the excavation height of the slope, and 24 3D models are established. The strength reduction method is used on foundation and roadbed soil with the Mohr-Coulomb yield criterion to calculate safety coefficient of stability.

The boundary conditions are: the bottom face is constrained fully, the three sides of the model are constrained normally, the side portion of excavation is symmetry constrained, and the slope and the top surface are free. The calculation parameters come from the data in the table.

Table 2 shows the stability safety factor corresponding to the different excavation width at different slope excavation heights by strength reduction method.

Table 2 Segments excavation and stability safety factor

\begin{tabular}{ccccc}
\hline excavation width $W / \mathrm{m}$ & \multicolumn{4}{c}{ slope height $H / \mathrm{m}$} \\
\cline { 2 - 5 } & 6 & 8 & 10 & 12 \\
\hline 6 & 2.76 & 2.46 & 1.95 & 1.70 \\
8 & 2.57 & 2.20 & 1.92 & 1.68 \\
10 & 2.35 & 2.00 & 1.82 & 1.65 \\
12 & 2.20 & 1.93 & 1.70 & 1.52 \\
14 & 2.20 & 1.90 & 1.65 & 1.45 \\
16 & 2.20 & 1.90 & 1.60 & 1.44 \\
\hline
\end{tabular}

The data in Table 2 show that when the ratio of width to height is 1 and the excavation height and width increase, the stability factor of safety continue to decrease. It explains that the ratio of width to height of excavation can not reflect the excavating slope stability. With the expansion of 
the excavation scale, the arching range also expanded, but the instability and slump of soil in the arch is also unacceptable.

Table 3 Stability calculations comparison table of two construction program

\begin{tabular}{|c|c|c|c|}
\hline $\begin{array}{l}\text { Excavation } \\
\text { scheme }\end{array}$ & $\begin{array}{c}\text { safety factor } \\
F_{\text {st }}\end{array}$ & Displacement cloud figure U & Remark \\
\hline & 2.67 & & Before excavation \\
\hline Full section & 1.61 & & After excavation \\
\hline \multirow[t]{2}{*}{$\begin{array}{l}\text { Staging and } \\
\text { grading }\end{array}$} & 1.84 & & Staging and grading \\
\hline & 2.65 & & $\begin{array}{l}\text { After retaining wall } \\
\text { construction }\end{array}$ \\
\hline
\end{tabular}

Table 3 shows that in front of and behind slope excavation retaining the shapes and positions of sliding surface were not the same. It was arc shape penetrating the toe in front before excavation and wedge shape after excavation. The retaining restored to the kick drum arc after the construction indicating the importance of strengthening the passive earth pressure area in front of the abutment and the timely construction of the pavement structure; after the retaining wall construction, the stability safety factor of soil the level of before excavation of the front slope of abutment, and the retaining effect of retaining wall was obvious; in the scheme of grading excavation and then construction of retaining wall in whole section, the stability safety factor was 1.61, while in the staging and grading excavation and support in time scheme, the stability safety factor was 1.84 , indicating the last one was more secure.

\section{Setup of the measuring equipment on the spot and collecting of measuring data}

In the column abutment slope reconstruction project of separated interchange at K100+462 in Rilan highway, the percent meter was installed at the top of retaining wall and the MGH-200 vibrating anchor dynamometer was installed on the anchor of failure tube pre-buried across the wall. The anchor tension and the displacement variation law at the top of the wall were tested when the adjacent segments were constructed, and the anti-pullout test of the anchor was carried out.

The displacement at the top of the wall and the anchor tension during the construction process were monitored on the site and the anti-anchor pullout test of the anchor was conducted to analyze the stability of the soil during the soil excavation and retaining wall construction process. The displacement at the top of the wall was mainly in construction. The anchor tension was no mutation. The retaining walls and the soil behind kept security and stability. Fracturing grouting reinforcement in the front and behind the abutment effectively improve the shear strength and anti-deformation ability of the soil in reinforced zone. There was no collapse, fall, slip phenomenon during the construction process and the reinforcement effect was obvious.

\section{Conclusions}


Through the implementation of scheduled programs for highway slope excavation, and the use of staging and grading excavation and prompt reinforcement measures of retaining wall construction, the retaining walls were established on the basis of slope excavation to make the project construction successful. Experiments on the field show that the project as a whole tends to be stable. The main conclusions are:

(1)During the excavation process of plan 1, the curve between the time and the displacement is very gentle at the beginning and slowly steepen over time. So we can obtain that the displacement of soil body mainly focus on the early time, so the impact of the subsequent excavation on the soil is not too great, and the displacement ratio between before and after is small.

(2)During the excavation process of plan 1, the curve between the time and the displacement is steep at the beginning and become slow relatively at last, which indicates that the displacement of soil is mainly in late, so there is a greater impact on soil by late excavation. With the late construction, it is found that there is shrinkage phenomenon experience of soil, which mainly occurs in the local area of the upper part of the soil. The reason for this phenomenon is that the pre-excavation make the initial stress of soil been released, leaving the soil displacement field in each section trend to distribute again.

(3) The stress field produced by two construction programs in the soil is almost consistent. In construction plan 1 the earth has a large distorted and a slow steady rate. The soil displacement in plan 2 is smaller than plan 1 . In the construction, the plane of construction should be enlarge to reduce the displacement among soils. So the usage of plan 2 is better.

\section{References}

[1]MENG Qing-shan,KONG Ling-wei,CHEN Neng-yuan,FAN Jian-hai,GUO Gang. Rock and Soil Mechanics, 2010, 31(11): 3379-3384. (in Chinese)

[2]TANG Ren-Hua, CHEN Chang-Fu. Rock and Soil Mechanics, 2012, 33(5): 1389-1394. (in Chinese)

[3]ZHU Wei-shen, WANG Ping. Chinese Journal of Rock Mechanics and Engineering,1992,11(4): 323-331. (in Chinese)

[4]DU Ju-hong. Research on construction processs mechanics of closely spaced tunnels .Tongji University,2008. (in Chinese)

[5]CHEN Zu-yu, NI Hong-liang, WANG Xiao-gang. Chinese Journal of Geotechnical Engineering,2001,23(5): 525-529. (in Chinese)

[6]ZHANG Jun-feng,DING Hua. Chinese Journal of Rock Mechanics and Engineering, 2005,24 (3): 365-370. (in Chinese)

[7]CHEN Zu-yu. Chinese Journal of Geotechnical Engineering, 2002,24 (01): 1-11. (in Chinese)

[8]ZHENG Ying-ren, ZHAO Shang-yi, LI An-hong, TANG Xiao-song. FEM limit analysis and its application in slope engineering. Beijing:China communication press,2011. (in Chinese) 